\title{
AUTOMATION SYSTEM APPLIED TO A PLASMA INERTIZATION PLANT
}

\author{
Alexandre M. F. Guimarães, Thiago Q. de Medeiros, Jader F. Sousa, Jurandir de O. Neto, Antônio H. F. \\ de Morais, Andrés O. Salazar, André L. Maitelli \\ Universidade Federal do Rio Grande do Norte - Laboratório LAMP, Departamento de Engenharia de Computação e \\ Automação - Campus Universitário, s/n - Lagoa Nova - CEP 59.072-970, C. P. 1512 , Natal, RN - Brasil \\ E-mails: alexandre@crn.inpe.br, thiago@crn.inpe.br, jadersousa@crn.inpe.br, jurandir@crn.inpe.br, andres@dca.ufrn.br, \\ maitelli@dca.ufrn.br, higormorais@crn.inpe.br \\ Jean P. Dubut \\ Instituto Nacional de Pesquisas Espaciais - INPE/CRN - Rua Carlos Serrano, 2073 - Lagoa Nova - CEP 59.001-970, C. P. \\ 130 - Natal, RN - Brasil \\ E-mail: jean@crn.inpe.br
}

\begin{abstract}
This article describes an automation system for a residues treatment plant based on thermal plasma. A compact PLC was used to activate several subsystems and to control the main reactor inner temperature using Fuzzy logic. A human-machine interface allows the monitoring of the variables and the activations of devices of the system remotely. An OPC communication is used to link the computer and the PLC.
\end{abstract}

Keywords - PLC, Fuzzy logic, human-machine interface, thermal plasma.

\section{INTRODUCTION}

Residues and waste contain an extremely hazardous potential for the environment. Ambient alteration via chemical and physical compounds or nature degradation produce elements that infiltrate in soil, going to underground deposits and compromising the atmosphere and the water sources used for the public supplying, agriculture and industries [1]. Its spread for the atmosphere is also considerable. Therefore they can be the origin of a great number of diseases. It is imperious to hinder this happens, or at least, to minimize this possibility.

How to do it? During the last 30 years, many developed countries limited the air and soil pollution by introducing satisfactory disposal management of the residues. For this, they developed a residues policy, which matches the development need with a pollution small impact on environment caused by the waste production. Special national agencies were created to regulate juridical questions concerning the residues disposal. In case of Europe, the European Community dictates these policies. In Brazil, the residues policies started to be delineated.

Nowadays, at Rio Grande do Norte state, the federal government have established laws and regulated norms. Regarding the kind of residue category is quite appropriate once it is less aggressive for the environment compared to the conventional methods of incineration.

The use of industrial torches based on thermal plasma

Manuscript received on May 30, 2006. First revision on August 14, 2006; second revision on September 29, 2006. Recommended by the Editor of the Special Section J. A. Pomilio. provides an efficient conversion of energy, with stable discharges; durable structures of the torch, besides other benefits [2][3]. Recent developments of the switching semiconductors and microprocessors allow the use of power supplies in high frequencies ( $\mathrm{MHz}$ range) with great reliability and reduced cost, resulting in high performance. The efficiency of the RF inverter is approximately 90\%, which relatively high if compared to conventional RF inverters of linear power supplies [4].

This work proposes the development of an automation system and central control applied to a petrochemical effluents and residues plant using thermal plasma, being part of a larger work. The treatment system is basically composed by a plasma torch, a reactor, an incineration chamber, cooling systems and a RF 50kW power supply. The whole system will be supervised by a dedicated computer based on a human-machine interface (HMI), where the operator can configure the system and have access to the information data of the whole device. A compact PLC is used to control the process and main reactor temperature.

\section{PLASMA RESIDUES TREATMENT}

Figure 1 presents the illustrative diagram of the treatment plant industrial residues, the power supply with its control and several associated subsystems. The equipment was designed to process $250 \mathrm{~kg}$ plastic residues or $750 \mathrm{~kg}$ of petrochemical effluents, with calorific power $30 \mathrm{~kJ} / \mathrm{kg}$ and $10 \mathrm{~kJ} / \mathrm{kg}$, respectively[5][6], resulting in a dissipated power of $50 \mathrm{~kW}$. The processing time was estimated of about 8 hours per day. In the first step of the project, energy recovery technique was not included, but will be implemented in the second step.

When cooling/ignition systems and feeding source are turned-on, the residues and/or petrochemical effluents are inserted in the feeder through a pneumatic door and sent step-by-step through a stepping motor to the main reactor for plasma torch processing. The inorganic part of the residues is transformed in a slag called "obsidian". The obsidian is destined to an appropriate container through another pneumatic door. The organic part produces gases that are burned in the secondary reactor in the presence of oxygen. To eliminate the small particles found in the gases, they are washed in the washer and liberated to the environment. 


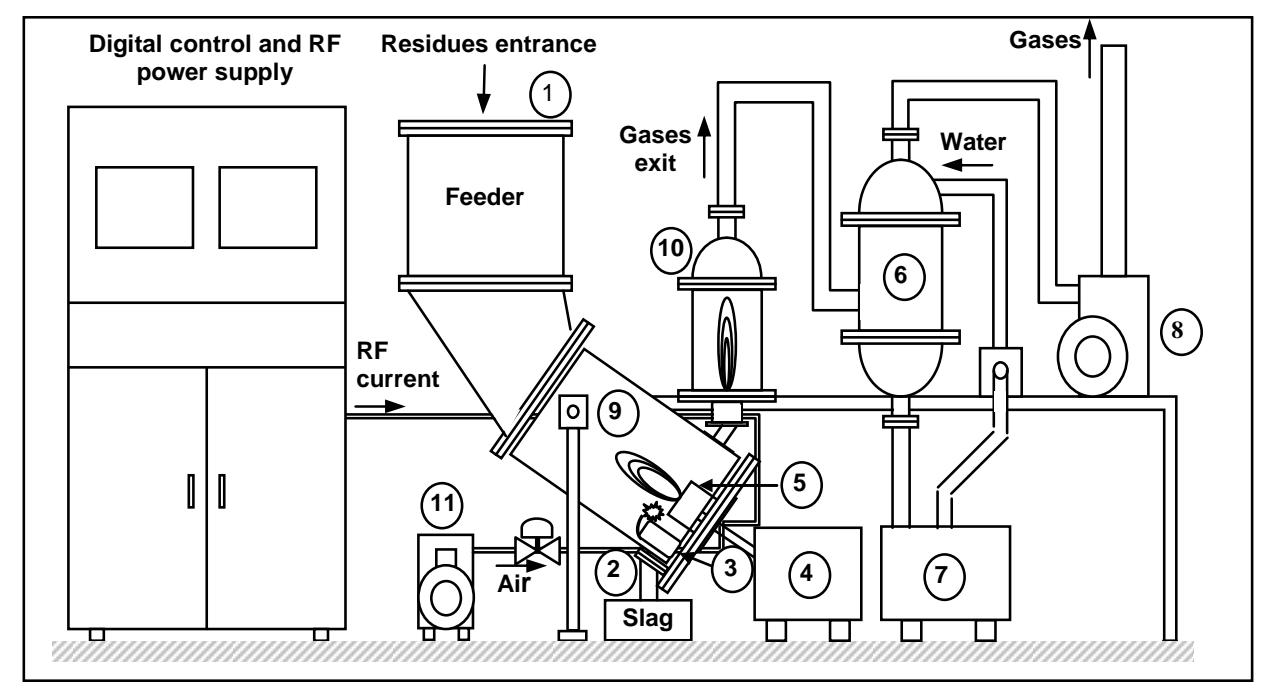

1 - Pneumatic door 1

2 - Pneumatic door 2

3 - Ignition system

4 - Torch cooling system

5 - RF Torch

6 - Gases washer

7 - Gases washer system

8 - Exhauster

9 - Main reactor

10 - Secondary reactor

11 - Air compressor

Fig. 1. Residues plasma inertization plant.

This way, it is expected approximately $95 \%$ reduction of residues [6][7].

The control system maintains the main reactor inner temperature according to the residue category. For this, it controls two important parameters that are provided for the plasma formation: plasma torch voltage and gas flow rate. The appropriate sequence switching for plasma torch activation is also implemented as well as the protection system for both the operator and residues treatment plant [8].

\section{POWER SUPPLY}

The RF power supply is composed by the AC/DC (boost rectifier) and $\mathrm{DC} / \mathrm{AC}$ (high frequency inverters) converters that supply $450 \mathrm{kHz}$ RF voltage for plasma torch operation.

The AC/DC converter is composed by a three-phase boost rectifier and accomplishes the power factor correction, supplying 800V@75A DC voltage. Figure 2 shows de AC/DC converter. It uses space vector modulation algorithm to shape the line current and to regulate the output voltage. The DC output voltage level of the AC/DC converter is controlled by the TMS320F2812 secondary DSP. The reference for this voltage is supplied by the Fuzzy controller of the PLC, varying from $550 \mathrm{~V}$ to $850 \mathrm{~V}$ according to the residue category.

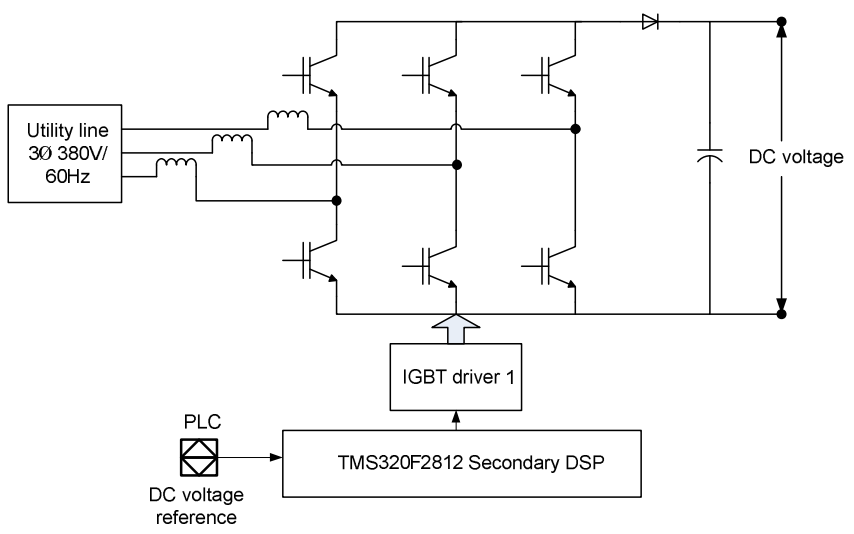

Fig. 2. AC/DC converter.
The DC/AC converter is composed by four series-resonant inverter modules configured to supply the $450 \mathrm{KHz} \mathrm{AC}$ voltage. A digital PLL algorithm driven by the TMS320F2812 main DSP controls the inverter switching frequency close to the resonant oscillation frequency of the plasma to achieve precise zero current switching operation so that the di/dt stresses on the insulated gate bipolar transistors (IGBTs) are minimized and switching occurs with negligible oscillations[16-18]. Figure 3 illustrates the DC/AC converter.

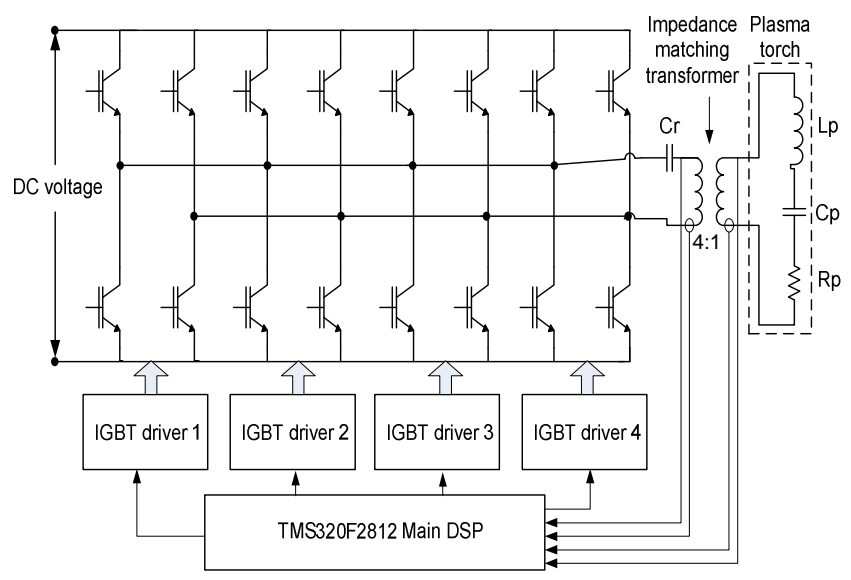

Fig. 3. DC/AC converter.

The use of a DSP-based control for both converters has the added advantage that the different control schemes requiring different heating periods and different adaptations of the plasma system can be implemented with modifications to the software alone and no changes to the hardware.

Serie-resonant capacitor $(\mathrm{Cr})$ and the plasma torch inductance accomplish the load current resonance. The plasma torch inductance $(\mathrm{Lp})$ and resistance $(\mathrm{Rp})$ value are about $3,7 \mu \mathrm{H}$ and $0,6 \Omega$, respectively. The tank circuit sets the resonant frequency and characteristic impedance of the system. An impedance matching transformer with a turns ratio of $4 / 1$ is used to isolate and match the impedances of the DC/AC converter and the load. 
Figure 4 shows a picture of the power supply.

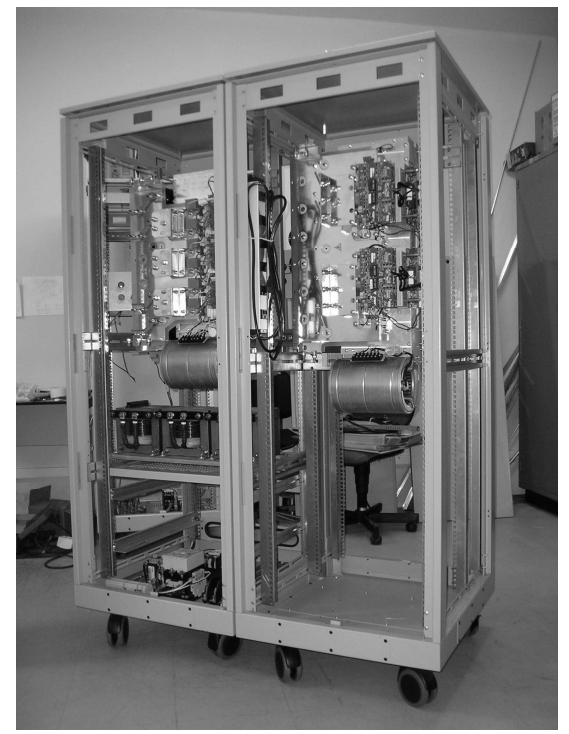

Fig. 4. Power supply.

\section{AUTOMATION SYSTEM}

The control system is provided for a PC computer equipped with a human-machine interface capable to manage the operation of the plasma torch plant. The interface was built in Labview graphic environment, and directed to give information about the status system, modify the operation parameters, and turn-on/turn-off the plant devices.

The PS4-341-MM1 PLC compact module [9][10] controls the temperature inside the reactor in a closed loop and activates other subsystems. The PLC system includes several protections to avoid accidents and damages in the equipments.

Figure 5 illustrates the complete control system and its subsystems. Figure 6 displays the diagram of the temperature control. An external loop maintains the main reactor inner temperature using Fuzzy logic, producing DC voltage references to control the $450 \mathrm{kHz}$ inverter and plasma gas flow rate. Due to the difficulty of modeling the plant parameters, the Fuzzy logic is cascaded with a conventional PID controller based on experimental tests [11][12]. The PLC used has Fuzzy and PID blocks that can be programmed.

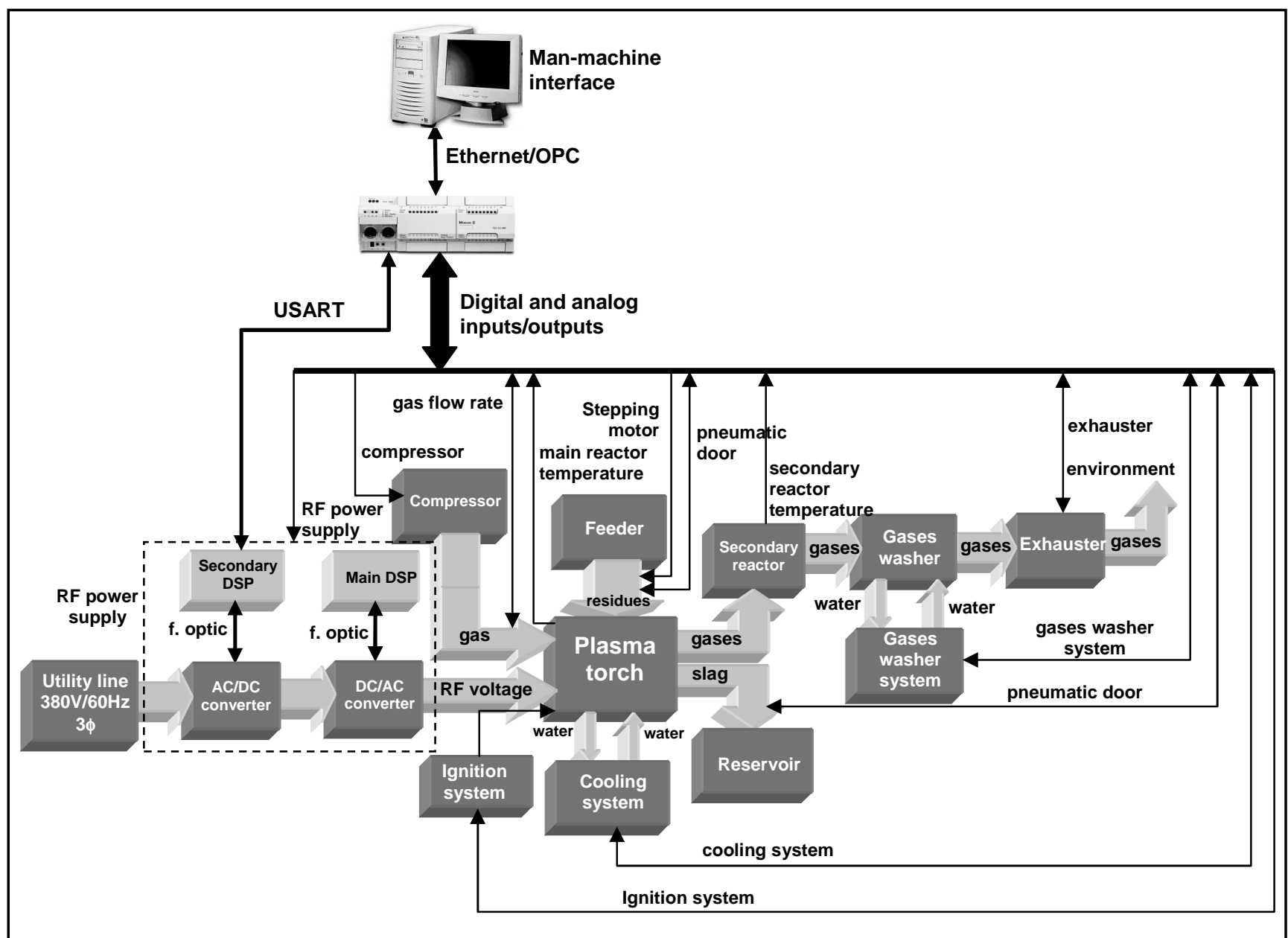

Fig. 5. Plasma treatment plant automation system. 


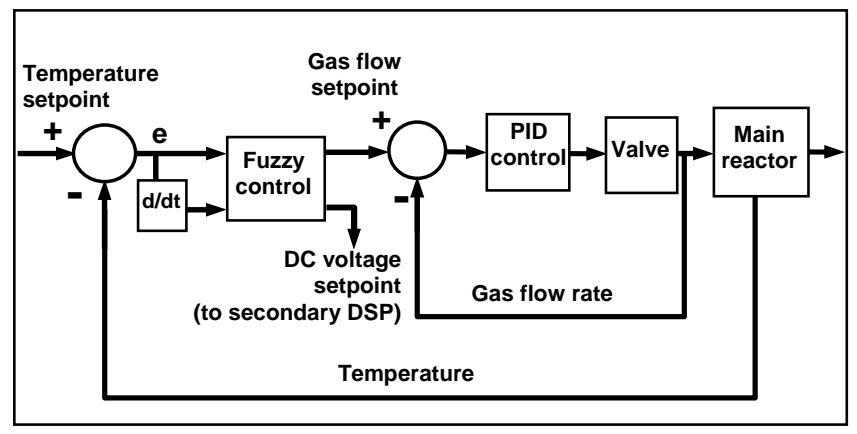

Fig. 6. Main reactor inner temperature control.

Fuzzy systems are relatively easy of using in practice and the mathematical knowledge is not complex. However, to program them a software engineer needs deep understanding of the industrial process inaccuracy and uncertainty [13-16].

An analog valve maintains constant the plasma temperature in the reactor by controlling the gas flow rate of plasma. An internal loop controls the plasma flow rate using a conventional PID control. The reactor temperature is set according to the kind and quantity of residues to be treated and previous control tests made in open loop. For complete molecular dissociation of the organic residues and vitrification of the metallic and/or ceramic residues, the temperature inside the reactor must reach up to approximately $1600^{\circ} \mathrm{C}$. To reduce cost, air is used as the plasma gas.

The communication between PLC and secondary DSP is made by an RS-232 interface. The PLC and the computer use the OPC (OLE for Process Control) to adjust the variables used by the HMI. One of the main advantages for using the OPC communication is the elimination of drivers. The use of drives presents problems when they make communication between different data sources, for instance between a plant device and computer or between two devices from different suppliers because of driver specification [19]. In fact, the non-drive OPC communication is becoming a standard link device for industrial applications. Moreover, nowadays professional from automation and TI areas are studying the best way of implementing the OPC communication in the industry

Figure 7 displays the representation of the links between the devices. The fiber optic is an excellent way of signal transmission and is immune to electromagnetic interferences (EMI) generated by RF power supply, bombs, and motors. The IGBT drivers use especial input/output connectors to link the fiber optic cables.

\section{A. Fuzzy logic rules}

Controllers PID are widely advised by literature for the control of temperature. But, due to the behavior of the load, the use of the PID control technique itself to control the main reactor inner temperature was not adequate to satisfactory performance of the system. On the other hand, it could be improved it by using a PID combined with a Fuzzy controller. It could be evidenced when it was implemented and a better performance was obtained. The controller could to reach values of setpoint in a faster and steady form. Also, It was evidenced a better effectiveness of the controller for changes of setpoint or disturbances values.

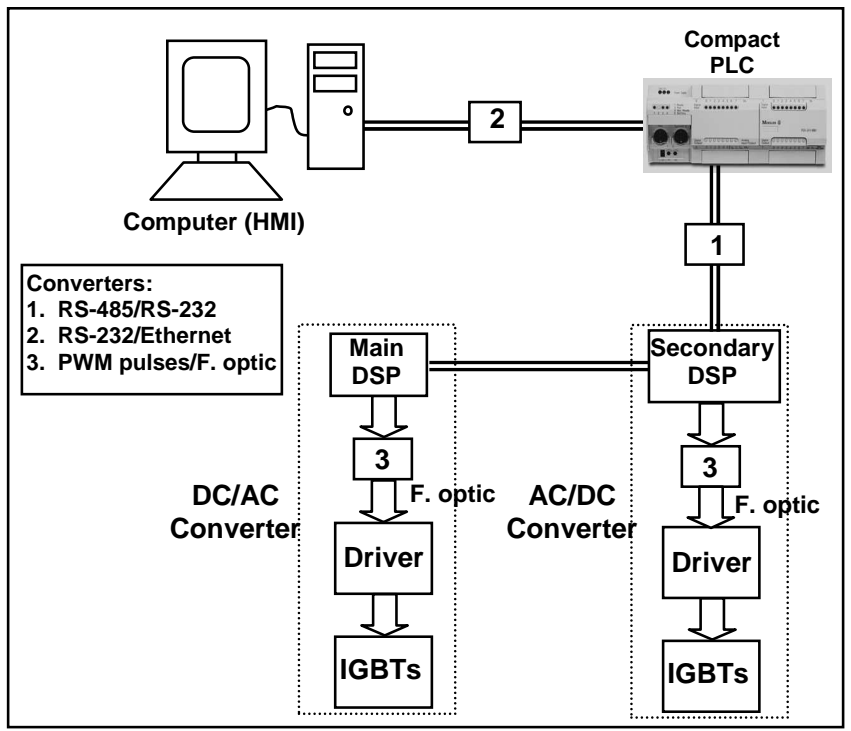

Fig. 7. Links between devices.

The Fuzzy logic control uses two input variables (variation and speed variation of the temperature error) and two output variables (the setpoint of the DC output voltage control - sent to the secondary DSP - and the setpoint of the gas flow rate control - using a classic PID controller). Therefore, the fuzzy controller is the process manager because it sets others setpoints controllers.

Each variable has its respective fuzzy inference functions, as shown in Figures 8 and 9.

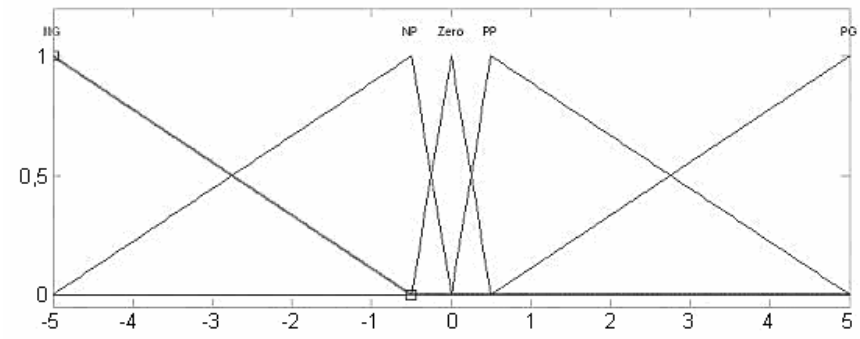

Fig. 8. Fuzzy inference functions of the temperature error variation - input variable 1.

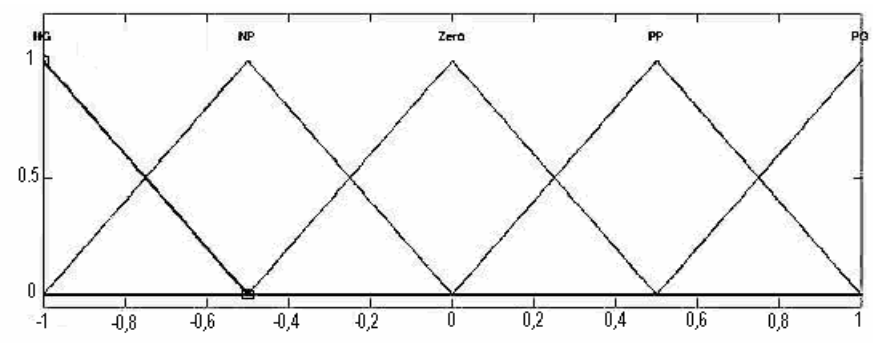

Fig. 9. Fuzzy inference functions of the speed variation of the temperature error- input variable 2.

Where NG is big negative, NP is small negative, PP is small positive and $\mathrm{PG}$ is big positive.

After elaborated the inference functions involved in the process control, it was made the rules of the fuzzy control law. All 15 control rules were formed by combinations of IF's between each set of the each variables involved in the process: 
- Rule 1: IF variable 1 is in the set Zero AND variable 2 is in the set NG THEN the output variable 1 will have the value 652 (652 Volts) and output variable 2 will have the value 300 (300 1/min);

- $\quad$ Rule 2 IF variable 1 is in the set Zero AND variable 2 is in the set NP THEN the output variable will have the value 646 (646 Volts) and output variable 2 will have the value 265 (265 1/min);

- $\quad$ Rule 3 IF variable 1 is in the set Zero AND variable 2 is in the set Zero THEN the output variable will have the value 640 (640 Volts) and output variable 2 will have the value 250 (250 1/min);

- $\quad$ Rule 4 IF variable 1 is in the set Zero AND variable 2 is in the set PP THEN the output variable will have the value 634 (634 Volts) and output variable 2 will have the value 280 (280 1/min);

- Rule 5 IF variable 1 is in the set Zero AND variable 2 is in the set PG THEN the output variable will have the value 628 (628 Volts) and output variable 2 will have the value 250 (250 1/min);

- Rule 6 IF variable 1 is in the set PP AND variable 2 is in the set NG THEN the output variable will have the value 730 (730 Volts) and output variable 2 will have the value 350 (350 1/min);

- $\quad$ Rule 7 IF variable 1 is in the set PP AND variable 2 is in the set NP THEN the output variable will have the value 712 (712 Volts) and output variable 2 will have the value 340 (340 1/min);

- $\quad$ Rule 8 IF variable 1 is in the set PP AND variable 2 is in the set Zero THEN the output variable will have the value 730 (730 Volts) and output variable 2 will have the value 400 (400 l/min);

- $\quad$ Rule 9 IF variable 1 is in the set PP AND variable 2 is in the set PP THEN the output variable will have the value 730 (730Volts) and output variable 2 will have the value 375 (375 1/min);

- $\quad$ Rule 10 IF variable 1 is in the set PP AND variable 2 is in the set PG THEN the output variable will have the 652 ( 652 Volts) and output variable 2 will have the value 265 (265 1/min);

- Rule 11 IF variable 1 is in the set PG AND variable 2 is in the set NG THEN the output variable will have the value 910 (910 Volts) and output variable 2 will have the value 700 (700 1/min);

- Rule 12 IF variable 1 is in the set PG AND variable 2 is in the set NP THEN the output variable will have the value 910 (910 Volts) and output variable 2 will have the value 600 (600 l/min);

- Rule 13 IF variable 1 is in the set PG AND variable 2 is in the set Zero THEN the output variable will have the value 850 ( 850 Volts) and output variable 2 will have the value 575 (575 1/min);

- Rule 14 IF variable 1 is in the set PG AND variable 2 is in the set PP THEN the output variable will have the value 832 (832 Volts) and output variable 2 will have the value 700 (700 1/min);

- $\quad$ Rule 15 IF variable 1 is in the set PG AND variable 2 is in the set PG THEN the output variable will have the value 832 (832 Volts) and output variable 2 will have the value 700 (700 1/min).

Where output variable 1 is the DC output voltage and variable 2 is the gas flow rate.

\section{HUMAN-MACHINE INTERFACE}

The HMI elaborated in Labview environment [19-21] supervises the plasma treatment plant, providing for the operator an easy interface to control the system with several information about the process status. Figures 10.(a) and (b) illustrate this interface. The monitoring screen in Figure. 10.(a) shows the main power control (Controle Principal), the motors/pumps status (Status dos Motores e Bombas) and real time reading of the process parameters (Dados Monitorados). The power control buttons (green \& red) in the main power control are respectively responsible for turning on/off the pumps, exhauster, compressor, etc. Similarly, the green \& red power buttons (Potência) are respectively responsible for turning on/off the ignition system and RF power supply. Finally, the green \& red buttons related to the residues feeding (Alimentação de Resíduos) and slag elimination (Eliminação da Escória) control respectively the opening and close of the reactor input/output pneumatic doors. These buttons are physically present in the power supply and control system racks too. Therefore, the user can control the plant devices locally or remotely.

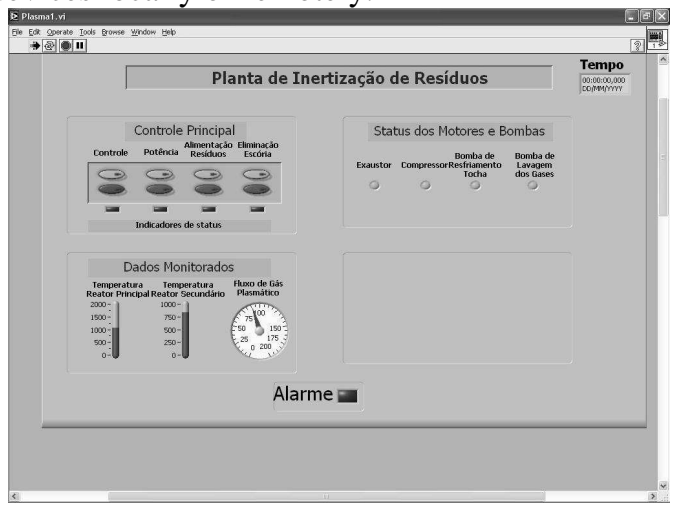

(a)

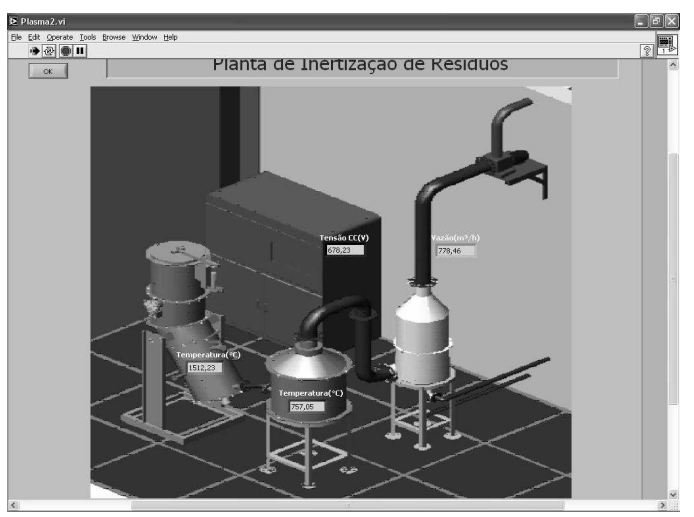

(b)

Fig. 10. Man-machine interface. (a) Parameters and status of the plant and (b) graphic visualization.

For each pair of buttons, there are virtual leds on the screen (see motors status in Figure 10.(a)), which monitors 
the physical button status alerting when the plant devices are turned on. On the screen area called "Dados Monitorados", it can be visualized the main process parameters such as main and secondary reactors temperatures and gas flow rate of the main reactor. Also, at the bottom of the screen, there is an alarm flag (Alarme) that alarm in case of abnormal situation. Figure 10.(b) shows the local variables in the plant. The user can use this second screen to locate a particular variable in the process during the operation.

\section{EXPERIMENTAL RESULTS}

Some results were obtained in order to verify the closed loop response of the main reactor inner temperature control. It was used the Labview software to record the waveforms.

Figure 11 shows load responses of the main reactor inner temperature. In Figure 11 (a) the main reactor inner temperature was stepped up from $500^{\circ} \mathrm{C}$ to $1000^{\circ} \mathrm{C}$; in Figure 11 (b) the temperature was stepped down from $1400^{\circ} \mathrm{C}$ to $1000^{\circ} \mathrm{C}$ and in Figure 11 (c) shows the disturbance caused by inserting of mixed residues composed by sand and coal. It can be seen that a satisfactory temperature control is verified. It was made several tuning adjustment in the Fuzzy logic rules to improve the performance of the system.

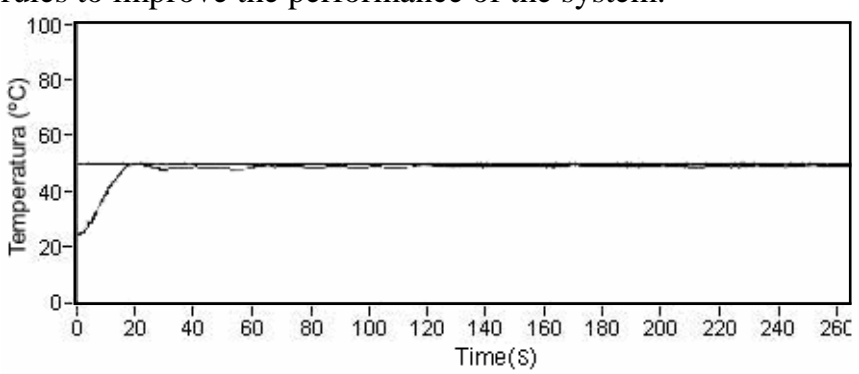

(a)

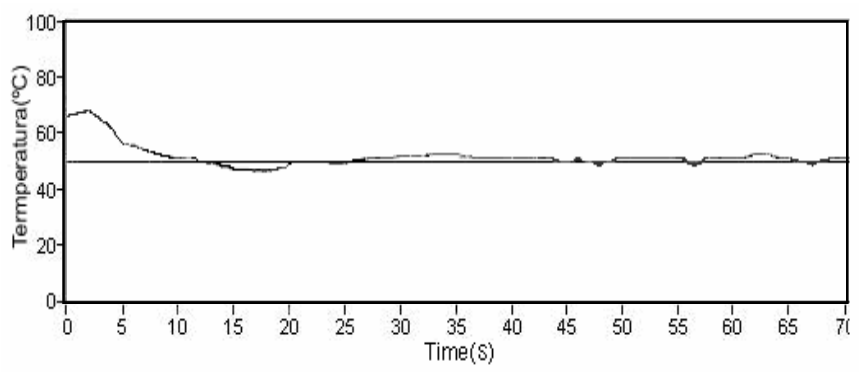

(b)

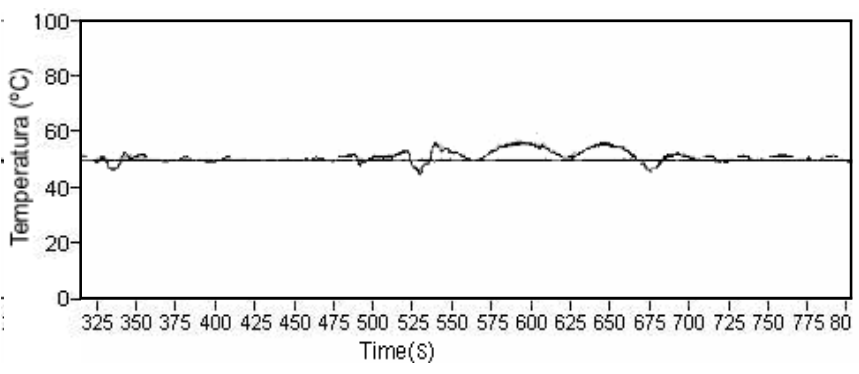

(c)

Fig. 11. Main reactor inner temperature. (a) $500^{\circ} \mathrm{C}$ step up, (b) $400^{\circ} \mathrm{C}$ step down and (c) disturbance. (scale*20)
The power supply output waveforms is shown in Figure 12. The load voltage shown in that figure is before the impedance matching transformer The voltage frequency is about $400 \mathrm{kHz}$. The PLL control of the DC/AC converter tries to keep the voltage frequency close to the resonant oscillation frequency of the load.

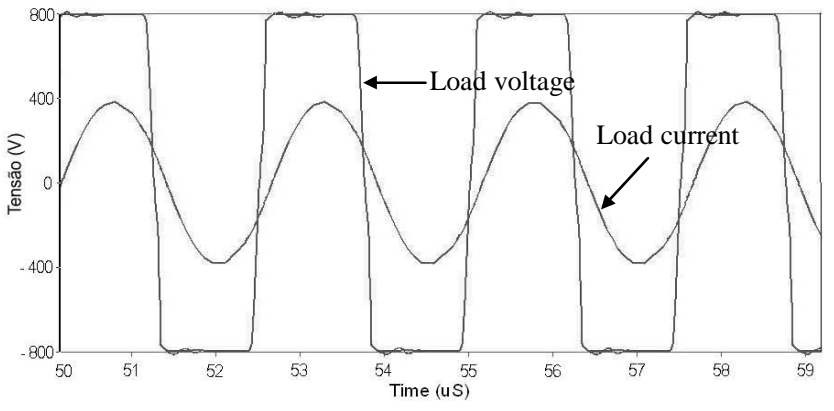

Fig. 12. Power supply output.

\section{CONCLUSIONS}

This work proposes the development of a control system for a plasma torch plant to be used in a treatment of petrochemical and hazardous residues. The control system consists of a computer equipped with HMI interface, a compact PLC and DSPs. The computer monitors and signals the whole process while the PLC and DSPs control the RF voltage switching for the plasma torch, the power plant devices used for system operation/protection, and the process temperature using Fuzzy logic and PID controllers. The Fuzzy logic was used to control the main reactor inner temperature due to the difficulty to obtain the mathematical model of the system. The temperature presented a good response to steps and disturbance, so the results were satisfactory.

The next step of this work is providing a cogeneration system to recover the plasma energy.

\section{ACKNOWLEDGMENT}

The group thanks FINEP \& CNPq for their financial support. The authors also acknowledge INPE/CRN for the supplied laboratory space.

\section{REFERENCES}

[1] R. A. A. Menezes, "Atuação do Grupo Kompac em sistemas de tratamento de resíduos sólidos", IV Workshop Brasil - Alemanha para o Intercâmbio em Ciências e Tecnologias Ambientais, 1999.

[2] G. Prieto, O. Prieto, C. R. Gay and T. Yamamoto, "Destruction of residual fumigant using a plasma reactor", IEEE Transactions on Plasma Science, vol. 30, 2002.

[3] G. A. Sites, "Plasma Arc Heating - an overview", VP HDR Power Systems, 2002.

[4] T. W Cheng, J. P Chu, C. C. Tzeng and Y. S Chen, "Treatment and recycling of incinerated ash using thermal plasma technology", Waste Management, 2002.

[5] M. C. Johnson, "On vitrifying wastes using a plasma arc torch", Environmental Health, Army Environmental Policy Institute, 2002. 
[6] P. Fauchais and A. Vardelle, "Thermal Plasmas", IEEE Transactions on Plasma Science, vol. 25, 1997.

[7] J. P. Sotelo, R. P Eguiluz, L. P Eguiluz, A. S. de Los Rios and G. C. Sanchez, "Plasma torch ignition by a half bridge resonant converter", IEEE Transactions on Plasma Science, Vol. 27, National Institute for Nuclear Research, México, 1999.

[8] F. Natale, Automação Industrial, Ed. Érica, 2000.

[9] W. Albrecht, Hardware and Engineering PS4-300, Moeller GmbH, Bonn, Germany, 1999.

[10]Main Catalogue Automation Systems 2004/2005, Moeller GmbH, Bonn, Germany, 2004.

[11]R. Tenhagen, Sucosoft S 40 Application Software Closed-Loop Control Toolbox - Reference Manual for Function Blocks, Moeller GmbH, Bonn, Germany, 1999.

[12]I. S. Shaw and M. Godoy Simões, Controle $e$ Modelagem Fuzzy, FAPESP, Ed. Edgar"Blücher Ltda., 1999.

[13]Z. Zhang, J. Rayner, A. Cheetham, and T. Lund, "A simplified fuzzy model to mimic a nonlinear system, applied to a plasma source", IEEE Transactions on Plasma Science, vol. 25, 1997.

[14]C. V Altrock, "Recent successful fuzzy logic applications in industrial automation", Fifth IEEE International Conference on Fuzzy Control, Vol. 3, Germany, 1996.

[15]A. M. Graham and M. Etezad-Amoli, "Design, implementation and simulation of a PLC based speed controller using fuzzy logic", IEEE Power Engineering Society Summer Meeting, Vol. 7, Reno, 2000.

[16]H. Wegmann, "Fuzzy control and neural networks industrial applications in the world of PLCs", Third IEEE Conf. on Control Applications, Vol. 2, Nürnberg, 1994.

[17] T. Adachi, K. Kondo, Y. Uesugi, M Takagi and S. Takamura, "Performance of Induction Thermal Plasmas Generated by SIT Inverter Power Supply", Plasma Chem. Plasma Process., Vol 7, 1998.

[18] N. S. Bayindir, O. Kükrer and M Yakup, "DSP-based PLL-controlled $50-100 \mathrm{kHz} \quad 20 \mathrm{~kW}$ high-frequency induction heating system for surface hardening and welding applications", IEEE Proc._Electr. Power Appl., vol. 150, 2003.

[19] K. P. Hermes, S40 OPC Server - User Interface, Moeller GmbH, Bonn, Germany, 2001.

[20] LabVIEW 7.0 - User Manual, National Instruments, 2003.

[21] L. K. Wells and J. Travis, LabVIEW for Everyone Graphical programming made even easier, Prentice Hall.

\section{BIOGRAPHIES}

Alexandre Magnus Fernandes Guimarães was born in Natal, RN, Brazil, in 1969. He received the B. S. and M. Eng. degrees in electrical engineering from the Federal University of Rio Grande do Norte.

$\mathrm{He}$ is currently working for a doctorate in electrical engineering. His research interests include digital control techniques, active power filter and switching power supply.
Andrés Ortiz Salazar was born Lima, Peru, in 1956. He received the B. S. in electronic engineering from the UNIPeru and M. Eng. and DSc. degrees from COPPE-UFRJ in 1989 and 1994, respectively.

He is presently a Professor in the Department of Electrical Engineering and the Department of Computer and Automation Engineering of the Federal University of Rio Grande do Norte, since 1994. He accomplished postdoctoral in the Science University of Tokyo - Japan. His research interests include power electronics, electrical machine of activate and automation and control of systems.

André Laurindo Maitelli was born in Bento Gonçalves, RS, Brazil, in 1965. He received the M. Eng. degree in Electrical Engineering from the University of Brasilia (UnB) in 1988 and the DSc. degree in Electronic Engineering from Aeronautics Technological Institute (ITA) in 1994.

$\mathrm{He}$ is professor of Federal University of Rio Grande do Norte since 1990 and currently he works in Computer and Automation Department. His research interests include theory and applications of predictive, adaptive and intelligent control systems, industrial instrumentation and measurement systems. He is currently manages many research projects applied in Petroleum Engineering.

Jean-Paul Dubut was born in France, in 1946, and it arrived at Brazil in 1970. He received the B. S. and M. Eng. degrees in electrical engineering from the Federal University of Rio Grande do Norte.

$\mathrm{He}$ is currently working for a doctorate in electrical engineering. His research interests include high frequency power inverters and PFC power supplies.

Antonio Higor Freire de Morais was born in Mossoró, RN, Brazil. He taking B. S. degree in computer and automation engineering from Federal University of Rio Grande do Norte

His research interests include process controls and petroleum engineering.

Thiago Queiroz de Medeiros was born in Natal, RN, Brazil, in 1984. He is taking B. S. degree in computer and automation engineering from Federal University of Rio Grande do Norte.

His research interests include industrial instrumentation, classic and intelligent process controls, FieldBus and petroleum engineering.

Jader Fernandes de Sousa was born in Natal, RN, Brazil, in 1981. He received the B.S degrees in electrical engineering from the Federal University of Rio Grande do Norte.

$\mathrm{He}$ is currently working for a master's degree in electrical engineering. His research interests include power of electronics, processing quality of the electrical energy, electronics control systems and electrical machine of activate.

Jurandir de Oliveira Neto was born in Natal. RN, Brazil, in 1979. He received the B.S degrees in computer and automation engineering from the Potiguar University.

$\mathrm{He}$ is currently working for a master's degree in electrical engineering. His research interests include power of electronics, automation and control of system, process of instrumentation. 